\title{
Assessment of Relative Anti-Diabetic Activity of Seven Extracts of Three Herbs in Alloxan Induced Diabetic Rats.
}

\author{
Shweta Sharma* and B.K. Mehta \\ Department of chemistry and biochemistry, Vikram University, Ujjain (M.P.) India
}

\begin{abstract}
In the present study, seven different extracts of three herbal drugs were evaluated for their comparative anti-hyperglycemic activity in alloxan $(120 \mathrm{mg} / \mathrm{kg})$ induced diabetic rats, metformin $(30 \mathrm{mg} / \mathrm{kg})$ was given as standard drug. In this research work, leave extracts of Pithecellobium dulce (PD) and bark extract of Butea monosperma (BM) \& Syzgium cumini (SC) were prepared. Diabetic animals were treated with 500 $\mathrm{mg} / \mathrm{kg}$ body weight individual test extract for successive seven days and results were analysed in overnight fasted animals. Acute toxicity tests and tissue histology were also done as supportive parameters. The obtained results indicated the significant $(P<0.01$ or more $)$ anti-diabetic potential of test extracts in experimental animals. Comparative analysis revealed that ethanolic extract of PD observed to be more protective than other extract used. For SC, both extracts were seemed to be equally effective. Though, aqueous extract of BM showed least protection than other two test extrats. These findings might help to find better extraction system to cure diabetes using traditional herbs.
\end{abstract}

Keywords: Anti-hyperglycemic, alloxan, Pithecellobium dulce, Butea monosperma, Syzgium cumini, oxidative stress, Diabetes mellitus, Antioxidant

\section{Introduction}

Diabetes mellitus (DM) is a world wide chronic metabolic disorder, which further provoke abnormalities in other biological systems. To cure these anomalies, natural as well synthetic drugs has been used from ages. As, bundles of side effects related to allopathic drugs have been reported [1,2] to get secure and sound treatment many people turned towards plant based medications. Literature revealed that $80 \%$ of the world population avail herbal therapeutic and their uses are rising every year [1]. DM is a treacherous human disorder affecting many from various walks of life and proving to be a major health problem. Alternate to synthetic drugs, to cure DM and related problems ayurvedic drugs are believed to be more appropriate and widely adopted by people [3].

Increased production of free radicals is a major factor that initiates and elevates diabetic complications [4]. Auto-oxidation of glucose due to persisting hyperglycaemia is also one of the major causes of oxidative stress, which promotes prostanoid synthesis, increased production of ketone bodies, polyol pathway, non specific-non enzymatic protein glycation and carbonylation [5].

Hundreds of herbs have been known to exhibit anti-oxidative property. Antioxidants either by inhibit over generation of such free radicals or by enhance their removal $[3,6,7]$. Similarly, a lot herbs also exert antihyperglycemic activity and also known to improve cellular antioxidant potency of the tissues, that protect tissues particularly $\beta$-cells which are more susceptible for free radical damage $[8,9]$. Few reports on the antioxidative and anti-diabetic potential of Pithecellobium dulce (PD) leaves and Butea monosperma (BM) \& Syzgium cumini (SC) barks have been documented [9-12]. But these were observed to be differentially effective depending on extraction solvent systems [13,14]. For example, many researchers reported the influence of diverse extraction solvents on the content of natural antioxidants in extracts. Solvents, such as methanol, ethanol, acetone, propenol, benzene and ethyl acetate etc., have been commonly used for the extraction of phenolics from fresh product. And thus generate assorted activity in biological system [2,4,6,7].

Since, to the best of our knowledge research on the evaluation of comparative anti-diabetic efficacies of different extracts of PD, BM and SC are scanty. Hence, there is a need to established scientific evidences regarding safety concern with maximum effectiveness of herbs for DM. Therefore, this study was designed particularly to find out the effects of different extracts of test herbs on blood glucose in alloxan induced rats.

\subsection{Chemicals}

\section{Materials and methods}

All chemicals were of the highest commercially available purity. The bark of SC \& BM and leaves of PD were collected from D-1 University campus, Dewas road, Ujjain, M.P., India. The identification of plant was done in Dept of Botany, Safia College of science, Bhopal. (M.P.) and the voucher specimen 436-438/ Bot /saf/13, was deposited in the Safia College of Science Bhopal (M.P.). 


\subsection{Preparation of extracts}

The leaves of PD were air dried and ground to a coarse powder. The powdered leaves were exhaustively extracted in soxhlet extractor with ethanol. Removal of solvent under reduced pressure afforded solid mass. The yield of ethanolic extract was stored for further research. Similar method was applied with hexane: benzene: acetone, $(1: 1: 1)$ solvents to prepare HBAPD extract.

The bark of BM was cleaned, air-dried at room temperature on a cool dry place keeping away from direct sunlight for 7 to 10 days and finally ground to a coarse powder. The powdered bark was exhaustively extracted in soxhlet extractor with ethanol (100\%), solvent was removed under reduced pressure. The obtained extract was stored at $4{ }^{\circ} \mathrm{C}$ for further use. Similar process was repeated to obtain Benzene: acetone (50:50) extract where, bark powder was extracted with benzene: acetone (50:50) solvents. To obtained aqueous extract of BM, the fine powder of bark dissolved in 20 volume double distilled water and stirred for 4 hours on magnetic stirrer. Then, the solution was kept for 24 hour at room temperature, filtrate was collected. The solvent was removed by using vacuum rotary evaporator, to yield powder. The powdered extract was stored at $4{ }^{\circ} \mathrm{C}$ for further work.

To prepare the extract of SC bark, the cleaned and air dried bark was ground to a coarse powder. The powdered bark was exhaustively extracted in similar way as describe above either with $100 \%$ ethanol or with 20 volume distilled water.

\subsection{Animals}

Healthy in-bred albino wistar rats of either sex (2-2.5 months old) were housed in polypropylene cages under constant temperature $\left(27 \pm 2^{\circ} \mathrm{C}\right)$ and photo-schedule $(14 \mathrm{~h} \mathrm{light}$ and $10 \mathrm{~h}$ dark $)$. They were provided rodent feed (Golden Feeds, New Delhi, India) ad libitum and had free access to boiled drinking water. The approval of departmental ethical committee for handling and maintenance for experimental animals was also obtained before starting the experiments.

\subsection{Acute oral toxicity study}

Acute oral toxicity study was carried out in young healthy female mice using the 'Limit dose test of up and down procedure' (UDP) according to Organization for Economic Corporation and Development guidelines 425. Dose up to $2000 \mathrm{mg} / \mathrm{kg}$ body weight (bw) was given in an increasing dose order and animals were checked for general behavioural, physical and autonomic changes.

\subsection{Sub acute oral toxicity study}

Sixty healthy Wister rats were divided into ten groups of six animals each and acclimatized for one week. Animals of groups 2-10 were rendered diabetic by single intraperitoneal injection of alloxan $(120 \mathrm{mg} / \mathrm{kg}$, in normal saline), whereas group 1 (control) animals were injected with normal saline. Hyperglycaemia was confirmed after 72 hours of alloxan treatment (Glucochek glucometer, Aspen Diagonstic, Delhi). Then, animals of group $3^{\text {rd }}$ received metformin $(30 \mathrm{mg} / \mathrm{kg}$, p.o.) and termed as stand group. Group 4th rats received aqueous extract of Syzygium cumini, (500mg/kg p.o.) termed as AESC group. Group 5th received ethanolic extract of S. cumini, (500mg/kg p.o.) termed as EESC group. Group 6th received aqueous extract of Butea monosperma, $(500 \mathrm{mg} / \mathrm{kg}$ p.o.) termed as AEBM group. Group 7 th received ethanolic extract of B. monosperma, $(500 \mathrm{mg} / \mathrm{kg}$ p.o.) termed as EEBM group. Group 8th received alloxan+ benzene:acetone (1:1) extract of B. monosperma, $(500 \mathrm{mg} / \mathrm{kg}$ p.o.) termed as BAEBM group. Group 9th received ethanolic extract of Pithecellobium dulce, $(500 \mathrm{mg} / \mathrm{kg}$ p.o.) termed as EEPD group. Group 10th received alloxan + hexane:benzene:acetone (1:1:1) extract of P. dulce, $\left(500 \mathrm{mg} / \mathrm{kg}\right.$ p.o.) termed as HBAPD group. The animals of group $1^{\text {st }}$ and $2^{\text {nd }}$ were administered with an equivalent amount of distilled water (the vehicle) for next 7 days. Dose was given at a fixed time (10:0011:00 AM) of the day to avoid circadian variation, if any. Body weight and water intake were measured (data not given). On the last day, blood samples were collected by tail vein of overnight fasted animals and blood glucose levels were estimated using an electronic glucometer. One rat from each group was randomly sacrificed by cervical dislocation for removing pancreas for histopathology.
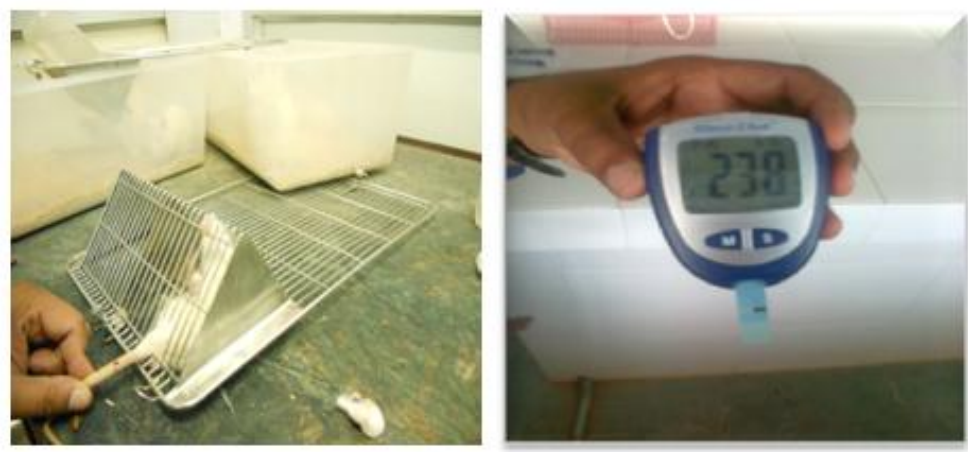

Blood sample collection by tail vein, Blood glucose measurement by glucometer. 


\subsection{Histological study}

Histopathological study was done using protocol of Deepa and Varlakshmi [15]. Tissues were fixed in $10 \%$ formaldehyde and then dehydrated in descending grades of isopropanol, cleared in xylene, and then embedded in molten paraffin wax. These fixed tissues were subsequently cut in to $5 \mu \mathrm{m}$ thick sections using microtome. The ribbons were then stained with hematoxylin and eosin and viewed under light microscope to study histopathological changes.

\subsection{Statistical analysis}

Data are expressed as mean \pm SE. Statistical analysis was done by using one -way ANOVA followed by unpaired student's t-test and p-values of $5 \%$ and less were considered as significant.

\section{Results}

In acute toxicity test, both extracts were found to be safe upto $2000 \mathrm{mg} / \mathrm{kg}$ body weight. While, in subacute toxicity examination, alloxan induced animals showed significant increased values of blood glucose $(\mathrm{P}<0.001)$ than normal control animals. Treatment with standard anti-diabetic drug was found to be linked with decreased blood glucose $(\mathrm{P}<0.001)$ than control animals. However, all the test extracts were seemed to effective against alloxan induced DM $(\mathrm{P}<0.001)$ for all. Administration of EESC, AESC and EEPD were observed to nearly equivalent to standard drug. Moreover, findings from comparative analysis showed that both ethanolic and aqueous extracts of SC showed similar protective effects, whereas, as compared to AEBM the other extracts of BM (EEBM and HBABM) seemed to be drastically more efficient ( $\mathrm{P}<0.001$ for both). Further, analysis showed that EEPD exhibited significantly increased anti-hyperglycaemic effects $(\mathrm{P}<0.001)$ than HBAPD. Histopathological investigation also exhibited similar results.

\begin{tabular}{|l|l|l|l|l|l|}
\hline Extract used & 100 & 200 & 500 & 1000 & 2000 \\
\hline AESC & All animals survived & All animals survived & All animals survived & All animals survived & All animals survived \\
\hline EESC & All animals survived & All animals survived & All animals survived & All animals survived & All animals survived \\
\hline AEBM & All animals survived & All animals survived & All animals survived & All animals survived & All animals survived \\
\hline EEBM & All animals survived & All animals survived & All animals survived & All animals survived & All animals survived \\
\hline BAEBM & All animals survived & All animals survived & All animals survived & All animals survived & One died \& rest survived \\
\hline EEPD & All animals survived & All animals survived & All animals survived & All animals survived & All animals survived \\
\hline HBAPD & All animals survived & All animals survived & All animals survived & All animals survived & One died \& rest survived \\
\hline
\end{tabular}

Where, (no. of animals in each group=3) drug doses in $\mathrm{mg} / \mathrm{kg}$ body weight. AESC (aqueous extract of SC); EESC, (ethanolic extract of SC); AEBM (aqueous extract of BM); EEBM (Ethanolic extract of BM), BAEBM (benzene:acetone (1:1) extract of BM), EEPD (ethanolic extract of PD), HBAPD (hexane:benzene:acetone $(1: 1: 1)$ extract of PD).

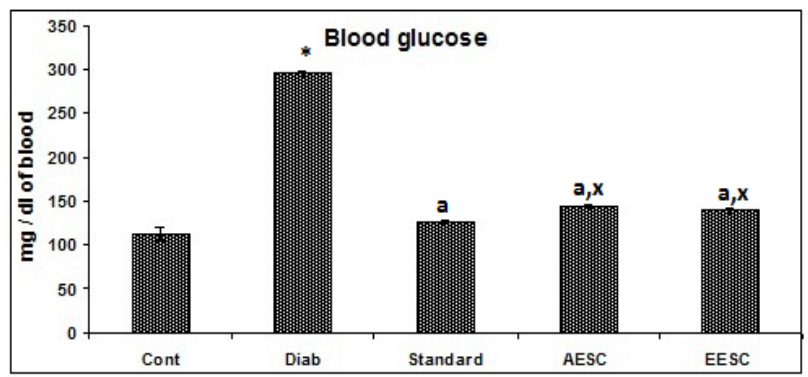

Figure 1: Cont (Normal control), Diab (alloxan treated diabetic group), Standard (metformin, $30 \mathrm{mg} / \mathrm{kg}$ ), AESC (alloxan+aqueous extract of SC); EESC, (alloxan+ethanolic extract of SC). Each bar represents the mean \pm SE $(\mathrm{n}=6), * \mathrm{P}<0.001$, as compared to normal control, ${ }^{\mathrm{a}} \mathrm{P}<0.05,{ }^{\mathrm{b}} \mathrm{P}<0.01$ and ${ }^{\mathrm{c}} \mathrm{P}<0.001$ as compared to alloxan treated group, ${ }^{\mathrm{x}} \mathrm{P}<0.05,{ }^{\mathrm{y}} \mathrm{P}<0.01$ and ${ }^{\mathrm{z}} \mathrm{P}<0.001$, as compared to standard drug.

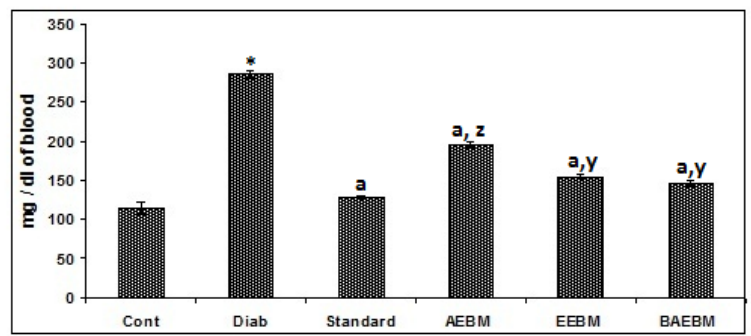

Figure 2: Cont (Normal control), Diab (alloxan treated diabetic group), Standard (metformin, $30 \mathrm{mg} / \mathrm{kg}$ ), AEBM (aqueous extract of BM); EEBM (Ethanolic extract of BM), BAEBM (benzene:acetone (1:1) extract of 
BM). Each bar represents the mean $\pm \mathrm{SE}(\mathrm{n}=6),{ }^{*} \mathrm{P}<0.001$, as compared to normal control, ${ }^{\mathrm{a}} \mathrm{P}<0.05,{ }^{\mathrm{b}} \mathrm{P}<0.01$ and ${ }^{\mathrm{c}} \mathrm{P}<0.001$ as compared to alloxan treated group, ${ }^{\mathrm{x}} \mathrm{P}<0.05,{ }^{\mathrm{y}} \mathrm{P}<0.01$ and ${ }^{\mathrm{z}} \mathrm{P}<0.001$, as compared to standard drug.

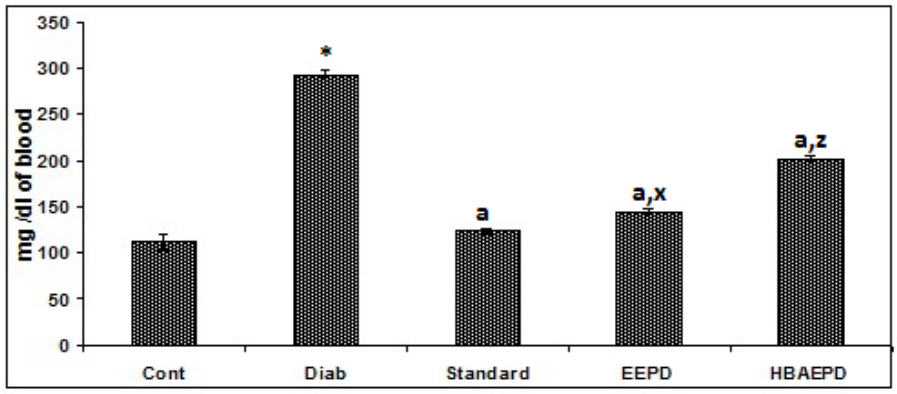

Figure 3: Cont (Normal control), Diab (alloxan treated diabetic group), Standard (metformin, $30 \mathrm{mg} / \mathrm{kg}$ ), EEPD (Alloxa+ ethanolic extract of PD) and HBAPD (alloxan + hexane:benzene:acetone (1:1:1) extract of PD). Each bar represents the mean $\pm \mathrm{SE}(\mathrm{n}=6),{ }^{*} \mathrm{P}<0.001$, as compared to normal control, ${ }^{\mathrm{a}} \mathrm{P}<0.05,{ }^{\mathrm{b}} \mathrm{P}<0.01$ and ${ }^{\mathrm{C}} \mathrm{P}<0.001$ as compared to alloxan treated group, ${ }^{\mathrm{x}} \mathrm{P}<0.05,{ }^{\mathrm{y}} \mathrm{P}<0.01$ and ${ }^{\mathrm{T}} \mathrm{P}<0.001$, as compared to standard drug.

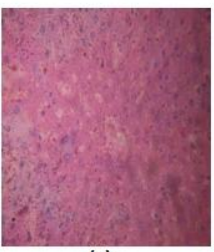

(a)

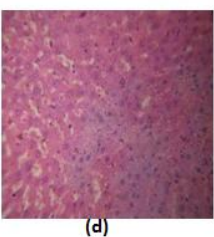

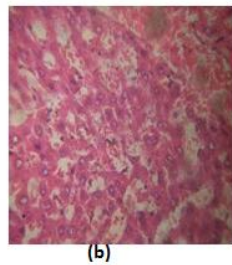
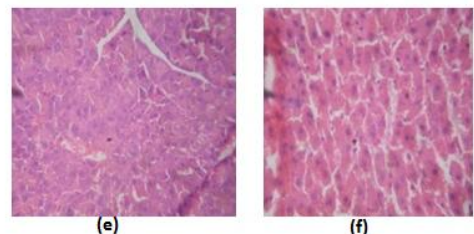
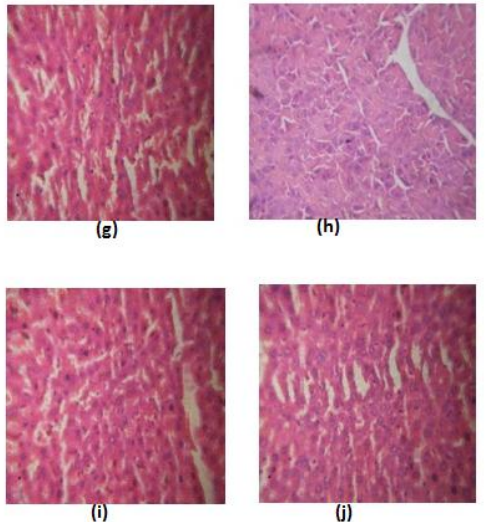

Figure 4: Histology of different experimental animals. Where, (a) Normal control, (b) diabetic control (c) metformin treated, (d) AESC (aqueous extract of SC), (e) EESC, (ethanolic extract of SC), (f) AEBM (aqueous extract of BM), (g) EEBM (Ethanolic extract of BM), (h) BAEBM (benzene:acetone (1:1) extract of BM), (i) EEPD (ethanolic extract of PD), (j) HBAPD (hexane:benzene:acetone (1:1:1) extract of PD).

\section{IDiscussion and conclusion}

Our finding clearly revealed that anti-diabetic potential of test extracts vary with the solvent used, which could be happened due to differential solubility of metabolites in different extraction systems. In our study, ethanolic extracts of PD and SC along with the AESC showed maximum inhibition of alloxan induced diabetes in rats. Alloxan induced increase in serum glucose level was consistent with the earlier reports [16,17]. In various drug treated groups with respect to glucose, a significant decrease was noticed indicating its diabetes ameliorating potential. Although, anti-diabetic effects of SC were reported earlier too but in the present investigation we aimed to reveal the comparison between to different extract and the obtained data were also compared with the anti-diabetic potential o five more extracts of BM and PD [10-14].

$\begin{array}{lll}\text { DOI: } 10.9790 / 1959-0505023439 & \text { www.iosrjournals.org } & 37 \mid \text { Page }\end{array}$


As, the PD leaves were already known for its medicinal uses for earache, leprosy, peptic ulcer, toothache, and venereal disease and also served as astringent, emollient, abortifacient, antidiabetic, anodyne and larvicidial remedy. Its anti-diabetic potential along with medicinal properties can be explained by the presence of cyclitol, dulcitol. Octacosanol, $\beta$ - D- glucoside, kaempferol-3- rhamnoside and other active compounds [12].

On the other hand, BM is generally recommended for skin diseases, muscular ailments and swellings, small-pox, and eczema. Due to its hepatoprotective efficacy also used in jaundice. In some other reports BM parts were found to exhibit anthelmintic, anti-bacterial antioxidative and hepato-protective in nature $[13,18]$. The different protective activities were observed to the linked with the presence of kino-tannic acid, gallic acid, pyro-catechin, palasitrin, and major glycosides as, alanind, allophanic acid, butolic acid, cyanidin, histidine, lupenone, lupeol, medicarpin, miroestrol, palasimide and shellolic acid, stigmasterol etc [18].

Whole plant of SC such as seed, fruit, leaves, flower, bark etc have been found to have medicinal values. For example its seeds, leaves and fruits are used to treat diarrhoea and the bark as an astringent. Obesity, menstrual disorders, cold infusion in intrinsic haemorrhage is also treatable with the use of bark. In the present investigation also both ethanolic and aqueous extracts were showed appreciable protection against alloxan induced DM [18,19]. Earlier worker have demonstrated the presence of active compounds such as eugenin, beneficial fatty acid ester, quercetin, kaempferol, bergenins, flavianoids tannins, pentacyclic triterpenoids, betulinic acid, ester of epi-friedelanol, friedelin etc. the presence of various active compounds, polyphenolic compounds, flavonoids, tannins etc are suppose to be responsible for its beneficial health effects [3-5,20].

Histopathological examination of liver sections of the normal control group demonstrated normal cellular architecture with separate hepatic cells and a central vein [15]. While, both induced groups exhibited disarrangement of hepatic cells with intense necrosis. The liver sections of the rat treated with different drug therapies showed more or less recovery of the tissue damage than induced group. Here, all three herbs were observed to be significantly effective against hyperglycaemia. Moreover, differential potencies of the different extracts of herbs indicated that different extracts possess different active compounds which served via different mechanism. Therefore, profitable use from the used herbs can be augmented with either additional alteration in the composition of extracts or by using mixed extracts therapies.

In conclusion, all the test herbs and their different extracts exhibited significant restoration in the increased blood glucose in diabetic rats indicated their worth-full use as anti-hyperglyceamic drug. In addition to this Both EESC and AESC were observed to equally effective, whereas, ethanolic extract of BM ad PD were found to be more effective and served as more potent drug to cure DM. Though, the seven extracts tested here were found to exhibited effective protection against DM, this was comparatively less effective than standard drug. In addition, HBAPD was seemed to least effective thus, solvent dependent protective potencies of the test extracts possibly indicated the presence of diverse group of active compounds in them which served via different pathways. Further investigations are needed to confirm the findings.

\section{Acknowledge}

Help of the co-scholars of School of studies in chemistry and biochemistry department, Vikram University, Ujjain (M.P.) are gratefully acknowledged.

\section{References}

[1] Cohen PA, Ernst E. Safety of Herbal Supplements: A Guide for Cardiologists. Cardiovas. Therap. 2010; 28:246-253.

[2] Posadzki P, Watson L, Ernst E. Contamination and adulteration of herbal medicinal products (HMPs): an overview of systematic reviews. Eur. J. Clin. Pharm. 2013; 69:295-307.

[3] Jarema M. Herb drug treatment. Neuro. Endocrinol. lett. 2008; 29:93-104.

[4] Pari, L., Latha M. Antidiabetic effect of Scoparia dulcis: Effect on lipid peroxidation in streptozotocin diabetes. Gen. Physiol. Biophys. 2005; 24:13-26.

[5] Kumawat M., Pahwa M. B., Gahlaut V. S., Singh N. Status of Antioxidant Enzymes and Lipid Peroxidation in Type 2 Diabetes Mellitus with Micro Vascular Complications. Open Endocrinol. 2009; 3:12-15.

[6] Chen CW, Ho CT. Antioxidant properties of polyphenols extracted from green and black tea. J. Food Lipids. 1995; 1:35-46.

[7] Chatterjee K, Ali KM, De D, Panda DK and Ghosh D. Antidiabetic and Antioxidative activity of Ethyl acetate Fraction of Hydromethanolic Extract of Seed of Eugenia jambolana Linn Through in-Vivo and in-Vitro Study and its Chromatographic Purification. Free Rad. Antioxi. 1995; 2:21-30.

[8] Maritim AC, Sanders RA, Watkins JB. Diabetes, Oxidative Stress, and Antioxidants: A Review. J. Biochem. Mol. Toxicol. 2003; 17:24-38.

[9] Rao MU, Sreenivasulu M, Chengaiah B, Reddy KJ, Chetty CM. Herbal Medicines for Diabetes Mellitus: A Rev. Int. J. PharmTech. Res. 2010; 2;1883-1892.

[10] Suguna L., Miriyala S. and Panchatcharam M., Efficacy of Butea monosperma on dermal wound healing in rats, Int. J. Biochem. Cell. Biol., 37, (3), 566-573, (2005).

[11] Misra GI and Nigam SK. Pithecolobium dulce a tree of commercial importance, Quart. J. Crude. Drug. Res., 1978; 16:158-62.

[12] Bopp A, De Bona KS, Belle LP, Moresco RN and Moretto MB. Syzygium cumini inhibits adenosine deaminase activity and reduces glucose levels in hyperglycemic patients, Funda. Clin. Pharmacol., 2009; 23:501-7.

[13] Saravanan G. and Leelavinothan P. Effects of Syzygium Cumini Bark on Blood Glucose, Plasma Insulin and C-peptide in Streptozotocin induced Diabetic rats, Int. J. Endocrinol. Metab., 2006; 4:96-105. 
[14] Saravanan G. and Pari L., Effect of syzygium cumini bark extract on plasma and tissue glycoproteins in streptozotocin induced diabetic rats, J. Cell \& Tissue Res., 2007; 1: 881-887.

[15] Deepa PR and Varlakshmi P. Protective effects of certoparin sodium, a low molecular weight heparin derivative, in experimental atherosclerosis. Clinica Chimica Acta, 2004; 339:105-115.

[16] Abebe W. Herbal medication: potential for adverse interactions with analgesic drugs. Journal of Clinical Pharmacy and Therapeutics. 2002; 27:391-401.

[17] Parmar HS and Kar A. Antiperoxidative, Antithyroidal, Antihyperglycemic and Cardioprotective Role of Citrus sinensis Peel Extract in Male Mice. Phytotherapy Research, 2008; 22:791-795.

[18] Belloso MO, Fortuny SR, Haruenkit R, Trakhtenberg S. Apple and pear peel and pulp and their influence on plasma lipids an antioxidant potentials in rats fed cholesterol-containing diets. J. Agric. Food Chem. 2003; 51;5780-5785.

[19] Niranjan PS, Kazuo K, Zhonghua J, Sukdeb B, Basudeb A and Tamotsu N. A minor acylated triterpenoid saponin from the seeds of Pithecellobium dulce, J. Chem., 1999; 3:558-559.

[20] Banarjee A. Studies on alkylated resin from Pithecellobium dulce, J. Ind. Chem. Soc., 2005; 82:186-187. 